\title{
The Relationship between Emotional Intelligence Ability and Teacher Efficacy
}

\author{
Sabina Valente ${ }^{1, *}$, Augusta Veiga-Branco ${ }^{2}$, Hugo Rebelo ${ }^{1}$, Abílio Afonso Lourenço ${ }^{3}$, \\ Ana Maria Cristóvão ${ }^{1}$ \\ ${ }^{1}$ Center for Research in Education and Psychology, University of Évora, Portugal \\ ${ }^{2}$ Polytechnic Institute of Bragança, Research in Education and Community Intervention, Portugal \\ ${ }^{3}$ Psychology and Education Research of Center School Group Alexandre Herculano, Portugal
}

Received December 12, 2019; Revised January 16, 2020; Accepted February 6, 2020

Copyright $\bigcirc 2020$ by authors, all rights reserved. Authors agree that this article remains permanently open access under the terms of the Creative Commons Attribution License 4.0 International License

\begin{abstract}
Emotional intelligence and self-efficacy are considered two of the most fundamental teachers' characteristics to create positive effects on students. Recent research on teacher efficacy has turned from a focus on mastery of content area and lesson plan development to the identification of teacher beliefs and the emotional self-regulation required for teaching and student learning. The purpose of this research was examined whether emotional intelligence abilities influence teacher efficacy. The relationship between teacher gender, length of teaching experience and academic formation with emotional intelligence abilities is also analyzed. The sample comprised 634 Portuguese school teachers. Data sources included the Emotional Skills and Competence Questionnaire for Teachers, and the Teacher Efficacy in Classroom Management and Discipline Scale. The findings, using structural equation modeling, showed that school teachers with greater skills at perceiving, understanding, expressing, classifying, managing and regulating emotions demonstrated greater levels of teacher efficacy. Therefore teachers' emotional intelligence abilities positively influence teacher efficacy. Having teachers who are apt to perceive and manage emotions will be salutary for the personal development of students, as well as for structuring a positive and self-regulating learning environment. So the results support the teachers' emotional intelligence ability to job performance, and add to literature suggesting that to succeed in the complex and demanding school setting, teachers must develop the necessary emotional skills for enhancing their efficacy. This research contributes to the importance of being created in the teachers' academic training, the emotional education discipline.
\end{abstract}

Keywords Emotional Intelligence, Teacher Efficacy, School teachers

\section{Introduction}

Teaching is an emotional activity, with teachers' work comprising a significant emotional workload, both in that it requires sensitivity and knowledge about how to manage and regulate emotions, both teachers and those of their students, to facilitate and optimize the quality of interpersonal relationships [1]. Therefore, emotional intelligence (EI) is an emerging topic of education research since emotional relationships between teachers and students are the more important part of the teaching and learning process.

Recent research on teacher efficacy has turned from a focus on mastery of content area and lesson plan development to the identification of teacher beliefs and the emotional self-regulation required for teaching and student learning [2]. Also, Iskandar, Majzub, and Mahmud [3] have pointed out that teachers' EI is highly relevant to their efficacy and to improve their performance. The literature supports the need to integrate emotional literacy into teacher training $[4,5,6,7]$.

A vast amount of research has documented positive associations between EI and teacher efficacy [8, 9, 10, 11], demonstrating that EI plays an important role in teacher efficacy. Starting from this foundation, this work focuses specifically on the influence of EI (the ability to perceive, understand, express, classify, manage and regulate emotions) on teacher efficacy. Teachers' personal and professional characteristics are also relevant in explaining their EI levels [7].

This is an exploratory study that analyzes how gender, teaching experience, and academic preparation influence EI ability, and, in turn, how EI ability relates to teacher 
efficacy. The following research question guided the investigation: "What is the relationship between EI ability and teacher efficacy?"

\section{Review on Literature}

\subsection{Teachers' Emotional Intelligence}

EI is the set of operations that processes and enhances emotions and it involves abstract thinking and problem solving [12]. The authors proposed a four-part, hierarchical model of EI includes four abilities: (a) emotional perception (in oneself and others); (b) emotional integration (use of emotions as a basis for cognitive reasoning); (c) understanding emotions (to identify why and how emotions are generated); and (d) emotion management (self-control, understanding one's feelings, and openness to growth). [12, pp.10] define EI as “...the ability to perceive accurately, appraise, and express emotion; the ability to access and/or generate feelings when they facilitate thought; the ability to understand emotion and emotional knowledge; and the ability to regulate emotions to promote emotional and intellectual growth."

The relationship between EI and work performance has been identified in several educational contexts $[3,5,7,13]$. The teachers' role in modern-day Portugal is highly challenging. Heavy workloads and time pressure are compounded by student discipline problems and a variety of pressures from school administrators, parents, and society as a whole. Meanwhile, since one of the most essential features of being a teacher and teaching is the emotional relationships that teachers have with their students, EI has been receiving increasing attention from educational researchers. Teaching and learning are not merely concerned with knowledge, cognition, and skill. They are also emotional practices [9].

Variables such as gender, teaching experience, and academic formation influence school teachers EI [7]. Studies have shown that women generally score higher on EI measures than men $[14,15]$. Also, teachers with more advanced degrees (e.g., Ph.D.) tend to have higher EI levels [16]. Research has also revealed, however, that length of teaching experience tends to correlate negatively with school teacher EI $[7,16]$.

Many studies have shown that EI is vital for school teachers' work performance and personal interactions [17]. It has been shown to correlate, for example, with all the following factors: well-being, job and life satisfaction [13]; teacher-student relationships, stress-tolerance and teaching satisfaction [18]; burnout prevention [19]; student satisfaction [20]; emotional labor strategies, teaching satisfaction, and the teaching and learning process [21]; and with classroom conflict management [7]. So, Mérida-López et al. [6] have concluded that school teachers with higher EI scores showed greater coping resilience and higher work engagement levels.

Besides, some researches have demonstrated a positive link between EI and teacher efficacy $[1,8,9,11]$. In sum, teacher EI also affects the way they think and develop efficacy beliefs about teaching.

\subsection{Teacher Efficacy}

For Gibson and Dembo [22] personal teaching efficacy consists of teacher beliefs that they master suitable teaching techniques and can help students learn, achieve more, do better than usual, and increase retention, among other skills. Besides, teacher efficacy is defined as teachers' beliefs about their ability to bring about ideal outcomes of student engagement and academic work, even among those students who may be problematic or indifferent [23]. Moreover, Bandura [24] defines self-efficacy as an individual's belief in their ability to organize and execute necessary courses of action to perform a specific task. In this view, self-efficacy strongly affects the choices people make, the energy they expend, and their determination in the face of challenge. Bandura then extends this concept to apply to teachers' perceptions of their skills in achieving their educational objectives, such as facilitating learning and encouraging student development.

Teacher efficacy is a significant personal resource when teachers are faced with their professional demands. Thus, some research has looked into teacher efficacy as an important construct in teacher education. Studies have reported positive associations between teacher efficacy and myriad factors, including professional performance and personal well-being at work [25]; teaching practices, enthusiasm, commitment, and in-class teaching behavior $[26,27,28,29]$; and job satisfaction [30]. Moreover, teachers with a greater sense of efficacy also exhibit better performance with classroom management and discipline [31] and greater determination with hostile students [22]. Besides, teachers with high efficacy beliefs manage negative affective experiences better than those with low efficacy beliefs who may experience greater levels of anxiety [9].

Based on this literature, the following hypotheses were formed: Hypothesis 1: A positive and statistically significant relationship is predicted between gender and EI abilities; Hypothesis 2: A positive and statistically significant relationship is predicted between academic formation and EI abilities; Hypothesis 3: A negative and statistically significant relationship is expected between teaching experience and EI abilities; Hypothesis 4: A positive and statistically significant relationship is expected between teachers' capacity to perceive and understand emotions and their ability to manage and regulate emotions; Hypothesis 5: A positive and statistically significant relationship is predicted between 
teachers' ability for expressing and classifying emotions and their ability to manage and regulate emotions; and Hypothesis 6: A positive and statistically significant relationship is expected between EI abilities and teacher efficacy.

\section{Materials and Methods}

\subsection{Participants}

A convenience sample was collected, consisting of 634 school teachers $\left(5^{\text {th }}\right.$ to $12^{\text {th }}$ grades $)$, working in Portuguese public schools. $69.2 \%$ of the participants were women. Of these, $3.0 \%$ had a bachelor's degree, $76.3 \%$ held a post-graduate degree, $19.9 \%$ had a master's, and 1.7\% a doctorate. Regarding teaching experience, $7.3 \%$ had less than ten years' teaching experience, $27.6 \%$ between 10 and 20 years, $42.1 \%$ between 21 to 30 years, and $23.0 \%$ had more than 30 years of teaching experience.

\subsection{Measures}

The Emotional Skills and Competence Questionnaire for Teachers (ESCQ-T) [32], adapted and validated from the Emotional Skills and Competence Questionnaire (ESCQ) [33], was used to collect data about teachers' perceptions about their EI ability. A 6-point Likert scale was used, scored from 1 (never) to 6 (always). ESCQ-T includes 45 items distributed among three subscales: (a) Perceive and understand emotions, 15 items (e.g., When I see how a student feels, I usually know what has happened to him.); (b) Express and classify emotions, 14 items (e.g., I can express my emotions well); and (c) Manage and regulate emotions, 16 items (e.g., I can stay in a good mood even if something unpleasant happens in the classroom). The Cronbach's $\alpha$ for the current sample had an adequate value of 90 .

The Teacher Efficacy in Classroom Management and Discipline Scale (TECMDS) [31] was also applied, as adapted from Gibson and Dembo [22]. It comprises 36-items, rated on a 5-point Likert scale, ranging from 1 (strongly disagree) to 5 (strongly agree), and measuring three subscales: (a) Personal teacher efficacy; (b) External influences; and (c) Classroom management efficacy and discipline. For this study, only the personal teacher efficacy was measure applied. It is made up of seven items $(\alpha=.79)$ (e.g., If one of my students cannot perform an activity, I can accurately evaluate the correct level of difficulty).

\subsection{Procedures}

All the research procedures received approval from the General Directorate of Education from the Ministry of Education, the researchers' institution's ethics committee, school directors, and teachers. Researchers administered the instruments, in groups of 15-20 teachers, during a session lasting from 30 minutes, in the school, during 2019. Teachers were informed about the research objective. The conventional ethical and deontological procedures were followed, especially regarding data confidentiality and participants' written consent to participate. Of all 650 surveys, $97.5 \%$ of teachers agreed to participate with the research, and only $2.46 \%$ were not filled in due to a lack of teacher availability. No missing data were recorded since all participants completed the questionnaires, and all the data were considered valid.

\subsection{Data Analysis}

The data was analyzed using SPSS/AMOS 25 [33]. Descriptive statistics, Pearson's correlation tests, and the Structural Equation Models (SEM) [34] were used. The Hoelter index [35] indicates the sufficiency of a sample size to be able to properly adjust the model and must be equal to or greater than 200 to indicate that the model closely represents the sample data. Pearson's r correlation tested the relationships between model variables.

For the descriptive data corresponding to variables included in SEM, the criteria used eliminated from consideration any asymmetry values greater than two or kurtosis scores higher than seven [36].

\section{Results and Discussion}

After data collection, a path analysis model was tested regarding the associated constructs and dimensions (cf. Figure 1).

Figure 1 specifies the hypothesized model for the 634 teachers. The overall goodness of fit are very robust $\left[\left(\chi^{2}=\right.\right.$ $6.235 ; p=.182 ; \chi^{2} / \mathrm{g} .1 .=1.559 ; \mathrm{GFI}=.997 ; \mathrm{AGFI}=.980 ;$ $\mathrm{CFI}=.984 ;$ TLI $=.914 ;$ RMSEA $=.030(\mathrm{LO} / .000-$ $\mathrm{HI} / .072$ )], confirming that the model represents relations among the existing variables in our empirical matrix. The Hoelter index values were also adjusted $[\mathrm{CN}=964(.05)$ and $1348(.01)]$. 


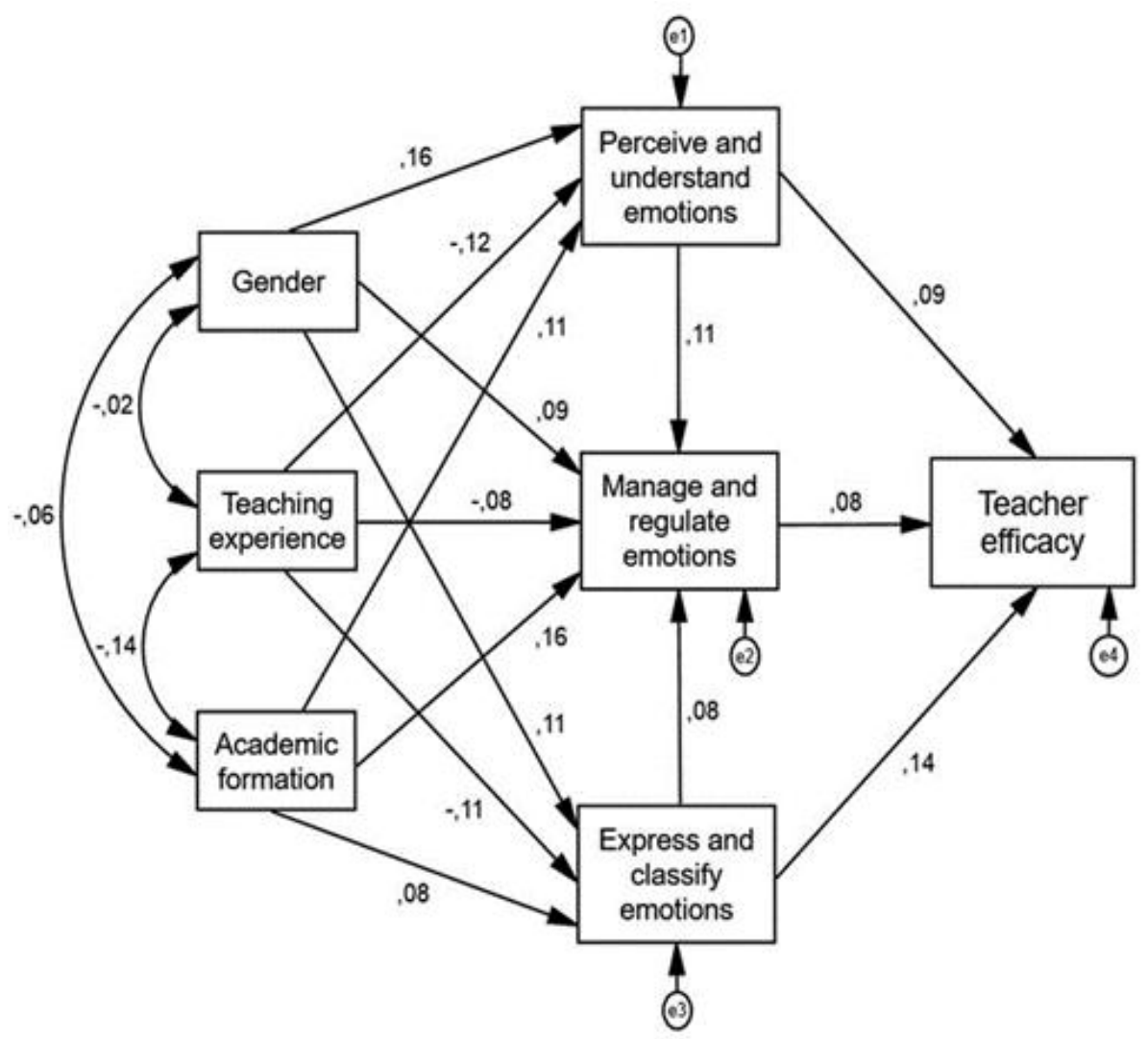

Figure 1. Structural equation model $(\mathrm{n}=634)$

Table 1. Descriptive Statistics Corresponding to the Studied Variables

\begin{tabular}{|c|c|c|c|c|c|c|}
\hline Variable & Min. & Max. & Mean & SD & Asymmetry & Kurtosis \\
\hline Gender & 1 & 2 & - & - & -.810 & -1.344 \\
\hline Teaching experience & 1 & 4 & - & - & -.294 & -.667 \\
\hline Academic training & 1 & 4 & - & - & 1.131 & 1.992 \\
\hline Perceive and understand emotions & 15 & 90 & 68.33 & 10.596 & -.485 & 2.832 \\
\hline Express and classify emotions & 14 & 84 & 60.56 & 17.909 & -1.255 & 1.041 \\
\hline Manage and regulate emotions & 16 & 96 & 73.69 & 16.126 & -1.515 & 3.409 \\
\hline Teacher efficacy & 7 & 15 & 19.62 & 7.773 & .180 & -.792 \\
\hline
\end{tabular}

Note. $\mathrm{SD}=$ Standard Deviation; Min. $=$ Minimum; Max. $=$ Maximum.

Table 1 displays the descriptive data corresponding to variables included in SEM. The criteria established are that asymmetry values greater than two and kurtosis higher than seven should not be considered. In this sample, none of the variables approximated these limits, so the estimation of the model fit was carried out.

In answering the general questions presented above, from the analysis of Table 2 and Figure 1, it can be seen that the hypotheses were confirmed and all were found to be statistically significant. Thus, women showed better results in all EI abilities, namely, positive correlations were found with the ability to perceive and understand emotions $(\beta=.16 ; p<.001)$, express and classify emotions $(\beta=.11, p<.05)$, and to manage and regulate emotions $(\beta$ $=.09 ; p<.05)$.
About teaching experience, teachers with more experience had shown to have less ability for perceiving and understanding emotions $(\beta=-.12 ; p<.01)$, less ability to express and classify emotions $(\beta=-.11 ; p<.01)$, and fewer ability to manage and regulate emotions $(\beta=-.08 ; p$ $<.05$ ).

Concerning academic formation, teachers with higher educational levels revealed higher EI in all dimensions.

Particularly regarding the ability to perceive and understand emotions $(\beta=.11 ; p<.01)$, to express and classify them $(\beta=.08 ; p<.05)$, and to manage and regulate, as well $(\beta=.16 ; p<.001)$. These relationships were positive and statistically significant.

When looking into the relationships between the dimensions of the two constructs, it can be seen that 
teachers with greater efficacy consistently scored higher for perceiving and understanding $(\beta=.09 ; p<.05)$, as well as having greater ability at expressing and classifying $(\beta=.14 ; p<.001)$, and at managing and regulating emotions $(\beta=.08 ; p<.05)$.

Table 2. Covariance Structure Contrast Hypothesized for the Sample

\begin{tabular}{|c|c|c|c|c|}
\hline Variables & EVnS & SEV & EE & $p$ \\
\hline Gender $\rightarrow$ PUE & 3.527 & .154 & .893 & $* * *$ \\
\hline Gender $\rightarrow$ ECE & 3.587 & .093 & 1.523 & .019 \\
\hline Gender $\rightarrow$ MRE & 2.830 & .081 & 1.355 & .037 \\
\hline Teaching experience $\rightarrow$ PUE & -1.316 & -.109 & .472 & .005 \\
\hline Teaching experience $\rightarrow$ ECE & -2.147 & -.105 & .806 & .008 \\
\hline Teaching experience $\rightarrow$ MRE & -1.694 & -.092 & .714 & .018 \\
\hline Academic formation $\rightarrow$ PUE & 2.142 & .102 & .824 & .009 \\
\hline Academic formation $\rightarrow$ ECE & 3.178 & .089 & 1.406 & .024 \\
\hline Academic formation $\rightarrow$ MRE & 4.855 & .152 & 1.242 & $* * *$ \\
\hline PUE $\rightarrow$ TE & .061 & .084 & .029 & .035 \\
\hline ECE $\rightarrow$ TE & .058 & .134 & .017 & $* * *$ \\
\hline MRE $\rightarrow$ TE & .038 & .080 & .019 & .046 \\
\hline PUE $\rightarrow$ MRE & .199 & .131 & .059 & $* * *$ \\
\hline ECE $\rightarrow$ MRE & .077 & .086 & .035 & .026 \\
\hline Covariances & & & & \\
\hline Teaching experience $\leftrightarrow$ & -.051 & -.116 & .018 & .004 \\
\hline Academic formation & -.016 & -.088 & .016 & .028 \\
\hline Teaching experience $\leftrightarrow$ Gender & -.018 & -.079 & .009 & .047 \\
\hline Academic formation $\leftrightarrow$ Gender & -19 & \\
\hline
\end{tabular}

Note. $\mathrm{PUE}=$ Perceive and Understand Emotions; $\mathrm{ECE}=$ Express and Classify Emotions; MRE = Manage and Regulate Emotions; TE = Teacher efficacy; EVnS = Estimated Values not Standardized; SEV = Standardized Estimated Values; $\mathrm{EE}=$ Estimated Errors; $p=$ significance level; $* * *=p<.001$

Teachers with greater ability for perceiving and understanding $(\beta=.11 ; p<.001)$, expressing and classifying emotions $(\beta=.08 ; p<.05)$ also showed a statistically significant greater ability to manage and regulate emotions.

Regarding exogenous variables, it is worth pointing out that the women had less teaching experience $(\beta=-.02 ; p$ $<.05)$ and lower levels of academic formation $(\beta=-.08 ; p$ $<.05)$.

Moreover, a negative and statistically significant relationship appeared between years of teaching experience and academic qualifications $(\beta=-.14 ; p<.01)$ (c.f. Table 2).

The multiple square correlations revealed that the exogenous variables, gender, teaching experience, and academic formation, accounted for approximately 5\% $\left(\eta^{2}=.049\right)$ of the ability to perceive and understand emotions, 3\% $\left(\eta^{2}=.030\right)$ was related to expressing and classifying emotions while managing and regulating emotions had a value close to $8 \%\left(\eta^{2}=.083\right)$.

Teacher efficacy was explained indirectly by the exogenous variables and directly by EI variables in approximately $4 \%\left(\eta^{2}=.037\right)$.

An analysis of Pearson's $r$ correlation between the variables also revealed that the ability to both perceive and understand emotions and to manage and regulate them were the only dimensions associated with all the others. Although the associations were low or very low, between $r=-.079 *$ and $r=.182 * *(r<.200$ indicates a very low; and between $.200-.399$ low), they were statistically significant, which indicates some cohesion between the variables under study. No statistically significant associations were found between teacher efficacy and gender or academic training.

\subsection{Discussion}

The main results of this research showed a positive correlation between EI abilities and teacher efficacy among Portuguese school teachers. They supported the hypotheses and provided empirical support for the theoretical link between these two constructs. Gender, length of teaching experience, and academic formation were also related to EI abilities.

In line with other studies $[14,15]$, a positive correlation also arose between gender and teacher EI, with the EI abilities being greater in women than men (Hypothesis 1). This finding provides empirical support for a gender difference in EI abilities. In so far as academic formation is concerned, the results indicated that teachers' with higher levels of training displayed the greatest levels in all three EI abilities (Hypothesis 2), which seconds previous research on Portuguese teachers [16]. The results also showed that teachers with greater amounts of teaching experience measured the lowest levels of EI abilities (Hypothesis 3). These results echo other studies of the Portuguese context $[7,16]$ that have identified that teachers are currently practicing their profession in a society marked by disequilibrium of multiple causes, including high levels of stress in the educational process, which destabilizes teachers as fatigue accumulates throughout their professional life.

Teachers with greater ability to perceive and understand emotions and to express and classify them demonstrated a greater ability to manage and regulate emotions (Hypothesis 4 and 5).

The ability to perceive and understand emotions, and to express and classify them is personal abilities that impose a systematic introspection, through the identification and interpretation of emotional states. Two fundamental processes are involved: the recognition and understanding of one's own emotions and those of others. If teachers do not identify emotions that students feel and express, especially if they contribute to the teachers' discomfort, nothing can be done to change them. A positive example is when a teacher perceives annoyance on students' faces and goes on to change the rhythm of the class or to give a more understandable explanation. At a more complex level, teachers with high capacity for emotional perception 
are those who perceive and are aware of the students' state of mind, knowing when and how to intervene, being able to identify the discrepancy between what the students may be feeling or thinking and what they say. This ability to differentiate discrepancies between students' verbal behavior and their expressions allows teachers to realize that, even if a student initially claims that nothing has happened, it might not be entirely true. The teacher may then offer to speak to the student and to listen to them to provide support and understanding [34].

Besides, the ability to manage and regulate emotions is considered higher-order ability and to achieve it, one must master the previous skills. In other words, the ability to moderate and manage one's emotional reactions in intense situations, positive or negative, is the hardest to reach and to wield with mastery. When teachers manage to regulate and manage their own emotions, they often manage to modify not only their feelings but those of the students [34]. This ability is the key to teacher performance since teachers must be able to manage their emotions in intense situations with students. The study confirmed that teachers' ability to perceive and understand emotions and to express and classify them influences their ability to manage and regulate emotions, while it is, in turn, vital for teacher success in educational settings, both in the interpersonal and professional domains.

Considering the relationships between the two constructs, teachers better skilled at perceiving and understanding emotions as well as expressing and classifying, managing and regulating them reveal higher levels of teacher efficacy (Hypothesis 6). This relationship is positive and statistically significant and it supports previous findings linking EI with higher levels of teacher efficacy $[1,8,9,11]$. Emotionally intelligent teachers have the skills to perceive their students beyond their behaviors and results. They are efficacious as they know how to support their classroom and their students, producing an effective teaching and learning process. In other words, teachers with high levels of EI ability are likely to develop a positive rapport with their students, to improve the teaching process, which, in turn, has a positive impact on students' learning and achievement. Therefore, how emotions are understood, reflected, and managed may hold promise for effective teaching, and for maximizing students' academic performance.

This study has limitations. The use of self-response questionnaires may have led participants to respond according to what they consider socially desirable. Moreover, the sample size limits the generalization of results. Future studies should look at this issue, using larger and more diversified samples with a wider range of levels of education and geographic location. Another limitation was that the teachers in the study were mostly women, limiting the variability of the sample. However, this reveals the reality of Portuguese schools, where women teachers exist in a much higher percentage than men [37].

A practical implication of these findings would suggest the need to make alterations to teacher training. Training programs should, therefore, be provided to teachers and teacher candidates to improve their skills. This training would also equip them to better face professional challenges and enhance their effectiveness. However, in Portugal, the factors that count in terms of the awarding of teaching jobs and promotions are primarily those of years' of teaching experience and evaluation of academic formation. These characteristics are vital, yet insufficient. It should be noted that Portuguese teacher academic formation does not yet value EI ability. Also, several studies have emphasized the significance of developing teachers' EI [4, 5, 6, 7].

\section{Conclusions}

The results showed positive relationships between EI abilities and teacher efficacy. Furthermore, they specify how teachers perceive and express their emotions and how they internalize their ability to regulate emotion affects their praxis, by way of their understanding of teacher efficacy.

Having teachers who are apt to perceive and manage the factors associated with their daily school activity will be salutary for the personal development of students, as well as for structuring a positive and self-regulating learning environment. It should also be pointed out that our results suggest that EI, i.e. the ability to perceive, understand, express, classify, manage and regulate emotions, all positively influence teacher efficacy. Given the challenging school context, it is expected that this framework of successive constructions and reconstructions will lead to the design of educational practice that will enable a redoubled commitment to this important endeavor.

Teachers skilled in perceiving and understanding emotions easily perceive their students' emotional state and can adapt their behavior and to change class activity when they perceive that the students are distracted. They have the sensitivity to criticize a more vulnerable student, to rearrange the classroom and to separate the students who are likely to cause the most friction [34]. Thus, teachers with more EI ability know suitable teaching techniques and can help students learn, to achieve more, to surpass themselves.

Future investigations into EI ability and teacher efficacy should be carried out to identify other personal, instructional and motivational variables to widen the range of variables under study. Longitudinal studies would be equally useful for verifying any potential variability in the results. Moreover, a qualitative methodology might uncover additional factors related to this interconnection between the variables under study, 
namely to deepen our understanding of the meanings attributed to teachers' perceptions and problems.

Finally, this study highlights the importance of teacher EI ability proactively and constructively. It is hoped these results will contribute to building up a knowledge base that might help practitioners better understand the emotional environment in which they work and which might foster change in pedagogical practices. Therefore, given the conclusions of this research, it is suggested that emotional education training should be introduced into the teachers' academic formation.

\section{REFERENCES}

[1] Poulou, M. S. (2016). An examination of the relationship among teachers' perceptions of social-emotional learning, teacher efficacy, teacher-student interactions, and students' behavioral difficulties. International Journal of School \& Educational Psychology, 5, 126-136. doi:10.1080/21683603.2016.1203851

[2] Bembenutty, H. (2007). Teachers' self-efficacy and self-regulation. Academic Exchange Quarterly, 11, $155-161$.

[3] Iskandar, I., Majzub, R. M., \& Mahmud,Z. (2009). Emotional quotient and work commitment among lecturers at an Indonesian university. Journal Pendidikan, 34 (1), $173-186$.

[4] Fernández-Berrocal, P., Cabello, R., \& Gutiérrez-Cobo, M. J. (2017). Avances en la investigación sobre competencias emocionales en educación. Revista Interuniversitaria de Formación del Profesorado, 88(31.1), 15-26.

[5] Hen, M., \& Sharabi-Nov, A. (2014). Teaching the teachers': Emotional intelligence training for teachers'.Teaching Education, 25, 375-390. doi: $10.1080 / 10476210.2014 .908838$

[6] Mérida-López, S., Extremera, N., Quintana-Orts, C., \& Rey, L. (2019). Sentir ilusión por el trabajo docente: inteligencia emocional y el papel del afrontamiento resiliente en un estudio con profesorado de secundaria. Revista de Psicología y Educación / Journal of Psychology and Education, 15(1), 67-76. doi:10.23923/rpye2020.01.186

[7] Valente, S. (2019). Influência da inteligência emocional na gestão de conflito na relação professor-aluno(s). Revista de Estudios e Investigación en Psicología y Educación, 6(2), 101-113. doi:10.17979/reipe.2019.6.2.5786

[8] Hassan, N., Jani, S. H. Md., Som, R. M., Hamid, N. Z. A., \& Azizam, N. A. (2015). The relationship between emotional intelligence and teaching effectiveness among lecturers at Universiti Teknologi MARA, PuncakAlam, Malaysia. International Journal of Social Science and Humanity, 5(1), 1-5. doi: 10.7763/IJSSH.2015.V5.411

[9] Koçoğlu, Z. (2011). Emotional intelligence and teacher efficacy: a study of Turkish EFL pre-service teachers. Teacher Development, 15(4), 471-484.doi:10.1080/13664530.2011.642647.
[10] Walter, O., Marcel, A. (2013). Emotional intelligence and teaching self-efficacy as predictors of teaching ability. Journal of Studies in Education, 3(3), 57-74. doi:10.5296/jse.v3i3.3785

[11] Wenn, B., Mulholland, R., Timmons, W., \& Zanker, Y. (2018). Towards a developing construct in dance education - exploring the relation of emotional intelligence to teacher's sense of efficacy and teaching experience among dance education student teachers in the United Kingdom. Research in Dance Education, 19(1), 14-38. doi: $10.1080 / 14647893.2017 .1354843$

[12] Mayer, J. D., \& Salovey, P. (1997). What is Emotional Intelligence? In P. Salovey \& J. Sluyter (Eds.), Emotional development and emotional intelligence: Educational implications (pp.3-31). New York: Basic Books.

[13] Mérida-López, S., \& Extremera, N. (2017). Emotional intelligence and teacher burnout: A systematic review. International Journal of Educational Research, 85, 121-130. doi:10.1016/j.ijer.2017.07.006

[14] Cabello, R., Sorrel, M. A., Fernández-Pinto, I., Extremera, N., \& Fernández-Berrocal, P. (2016). Age and gender differences in ability emotional intelligence in adults: A cross-sectional study. Developmental Psychology, 52(9), 1486-1492. doi:10.1037/dev0000191

[15] Sangeetha, N. (2017). A study on factors influencing emotional intelligence of teachers of management education in Coimbatore city. International Journal of Advanced Research, 5(3), 1490-1500. doi:10.21474/IJAR01/3657

[16] Sousa, R. L. V. (2011). Inteligência emocional dos professores e vulnerabilidade ao stress em contexto escolar. Dissertação de Mestrado. Funchal: Universidade da Madeira.

[17] Asrar-ul-Haqa, M., Anwarb, S., \& Hassanc, M. (2017). Impact of emotional intelligence on teacher's performance in higher education institutions of Pakistan. Future Business Journal, 3, 87-97. doi:10.1016/j.fbj.2017.05.003

[18] Hopman, J. A. B., Tick, N. T., van der Ende, J., Wubbels, T., Verhulst, F. C., Maras, A.,. . ., \& van Lier, P. A. C. (2018). Special education teachers' relationships with students and self-efficacy moderate associations between classroom-level disruptive behaviors and emotional exhaustion.

Teaching and Teacher Education, 75, 21-30. doi: $10.1016 /$ j.tate 2018.06 .004

[19] Schoeps, K., Tamarit, A., Barrera, U., \& Barrón, R. G. (2019). Effects of emotional skills training to prevent burnout syndrome in school teachers. Ansiedad y Estrés 25, 7-13. doi:10.1016/j.anyes.2019.01.002

[20] Maamari, B. E., \& Majdalani, J. F. (2019). The effect of highly emotionally intelligent teachers on their students'satisfaction". International Journal of Educational Management, 179-193.doi:10.1108/IJEM-11-2017-0338

[21] Yin, H., Lee, J. C. K., Zhang, Z., \& Jin, Y. (2013). Exploring the relationship among teachers' emotional intelligence, emotional labor strategies and teaching satisfaction. Teaching and Teacher Education, 35, 137-145. doi:10.1016/j.tate.2013.06.006 
[22] Gibson, S., \& Dembo, M. H. (1984). Teacher efficacy: a construct validation. Journal of Educational Psychology, 76(4), 569-582. doi:10.1037/0022-0663.76.4.569.

[23] Tschannen-Moran, M., \& A. W. Hoy (2001). Teacher Efficacy: Capturing an Elusive Construct. Teaching and Teacher Education, 17(7), 783-805. doi:10.1016/S0742-051X(01)00036-1.

[24] Bandura, A. (1997). Self-Efficacy: The Exercise of Control. New York: W H Freeman/Times Books/ Henry Holt.

[25] Klassen, R. M., \& Chiu, M. M. (2010). Effects on teachers' self-efficacy and job satisfaction: Teacher gender, years of experience, and job stress. Journal of Educational Psychology, 102, 741-756. doi: 10.1037/a0019237

[26] Betoret, F. D. (2009). Self - efficacy, school resources, job stressors and burnout among Spanish primary and secondary school teachers: a structural equation approach. Educational Psychology: An International Journal of Experimental Educational Psychology, 29(1), 45-68.

[27] DeMauro, A. A., \& Jennings, P. A. (2016). Pre-service teachers' efficacy beliefs and emotional states. Emotional and Behavioural Difficulties, 21(1), 119-132. doi: $10.1080 / 13632752.2015 .1120057$

[28] Dicke, T., Parker, P. D., Marsh, H. W., Kunter, M., Schmeck, A., \& Leutner, D. (2014). Self-efficacy in classroom management, classroom disturbances, and emotional exhaustion: A moderated mediation analysis of teacher candidates. Journal of Educational Psychology, 106, 569-583. doi:10.1037/a0035504

[29] Skaalvik, E. M., \& Skaalvik, S. (2007). Dimensions of teacher self-efficacy and relations with strain factors, perceived collective teacher efficacy, and teacher burnout. Journal of Educational Psychology, 99(3), 611-625. doi: 10.1037/0022-0663.99.3.611

[30] Caprara, G. V., Barbaranelli, C., Steca P., \& Malone, P. S. (2006). Teachers' self-efficacy beliefs as determinants of job satisfaction and students' academic achievement: a study at the school level. Journal of School Psychology, 44(6), 473-490. doi:10.1016/j.jsp.2006.09.001.

[31] Emmer, E. T., \& Hickman, J. (1991). Teacher efficacy in classroom management and discipline. Educational and Psychological Measurement, 51(3), 755-765. doi:10.1177/ 0013164491513027.

[32] Valente, S., \& Lourenço, A. A. (peer review). Questionário de inteligência emocional do professor: adaptação e validação do "Emotional Skills and Competence Questionnaire". Revista de Estudios e Investigación en Psicología y Educación.

[33] Taksic', V. (2000). Emotional Skills and Competence Questionnaire. Rijeka/Croatia, Author's Edition.

[34] Fernández-Berrocal, P., \& Extremera, N. (2005). La inteligencia emocional y la educación de las emociones desde el modelo de Mayer y Salovey. Revista Interuniversitaria de Formación del Profesorado, 19(3), 63-69.

[35] Hoelter, J. W. (1983). The analysis of covariance structures: Goodness-of-fit indices. Sociological Methods and Research, doi: $10.1177 / 0049124183011003003$

[36] Finney, S. \& DiStefano, C. (2013). Nonnormal and categorical data in structural equation models. In G. R. Hancock \& R. O. Mueller (Ed.), A second course in structural equation modeling, (pp. 439-492). Publisher: Information Age.

[37] PORDATA (2018). Docentes do sexo feminino em \% dos docentes em exercício nos ensinos pré-escolar, básico e secundário: total e por nível de ensino. Lisboa: FFMS. Available inhttps://www.pordata.pt/Portugal/Docentes + do + sexo + fe minino + em + percentagem + dos + docentes + em + exerc $\% \mathrm{c} 3 \%$ adcio + nos + ensinos + pr $\%$ c $3 \% a 9+$ escolar $++b \% c 3 \% a 1$ sico + e+secund $\%$ c3\%al rio + total $+\mathrm{e}+$ por $+\mathrm{n} \% \mathrm{c} 3 \%$ advel $+\mathrm{de}+$ ensin o-782 